\title{
EXPOSURE CRITERIA FOR EVALUATING LUMBAR SPINE LOAD
}

\author{
Lenka Pešáková1, 3 , Jana Hlávková2, Marie Nakládalová1, Pavel Urban²,4, Petr Gad’ourek², Tomáš Tichý2, \\ Alena Boriková1, Andrea Laštovková4, Daniela Pelclová \\ ${ }^{1}$ Department of Occupational Medicine, Faculty of Medicine and Dentistry, Palacký University Olomouc and University Hospital Olomouc, \\ Olomouc, Czech Republic \\ ${ }^{2}$ National Institute of Public Health, Prague, Czech Republic \\ ${ }^{3}$ Regional Public Health Authority of the Olomouc Region, Olomouc, Czech Republic \\ ${ }^{4}$ Department of Occupational Medicine, First Faculty of Medicine, Charles University and General University Hospital in Prague, Prague, Czech \\ Republic
}

\section{SUMMARY}

Objective: As a part of regular revision of the List of Occupational Diseases in the Czech Republic, efforts have been made to add a new item so that lumbar spine disease caused by overload may be recognized as occupational one, with adherence to the valid national rules, that is, clinical criteria are met and objective assessment confirms working conditions under which, according to recent scientific knowledge, such an occupational disease develops. The aim is to provide information on the use of a proposed method for working condition assessment in a real setting, based on the initial experiences gained from a pilot study carried out to validate the method.

Methods: Working conditions were assessed in 55 individuals with chronic low back pain (25 males, 30 females; mean age 45.6 years; mean length of employment 15.6 years). The assessment was based on estimating compressive force on the $L 4 / L 5$ intervertebral disc when performing potentially high-risk work tasks which were entered into four types of checklists throughout their work shifts. The compression values were calculated using a special module that was developed.

Results: In 24 cases comprehensive assessment of all tasks performed showed fulfillment of the proposed criteria of working conditions needed for recognition of occupational disease. Those included healthcare, foundry and forest workers, production operators, cabinetmakers, locksmiths, bricklayers, etc. In all the cases, lumbar spine overload was associated with work tasks requiring combinations of manual handling of objects and trunk rotation or bending. The criteria were not met in 31 subjects. The mean length of employment was 15.4 and 15.8 years in patients who met and did not meet the proposed criteria, respectively.

Conclusion: The proposed method proved to be applicable in occupational hygiene evaluation in a real setting.

Key words: lumbar spine overload, checklists, chronic lumbar spine diseases, occupational hygiene criteria, occupational risk factors

Address for correspondence: L. Pešáková, Regional Public Health Authority of the Olomouc Region, Wolkerova 6, 77911 Olomouc, Czech Republic. E-mail: lenka.pesakova@khsolc.cz

https://doi.org/10.21101/cejph.a4941

\section{INTRODUCTION}

Lifetime prevalence of low back pain is estimated at $60-85 \%$ $(1,2)$. The development of spinal diseases is thought to be linked with individual, psychosocial and physical factors including mechanical overload. A meta-analysis of 40 epidemiological studies showed a strong association between low back pain and tasks related to manual materials handling and accompanied by frequent bending and twisting of the trunk, postural stress, high physical workload and whole-body vibration (3). Manipulating with heavy objects accelerates degenerative changes in the lumbar spine so that they occur 8-10 years earlier on average than in the general population (4). In workers, lumbar spine problems worsen after a mean of 10-12 years of exposure (5). In many European countries, lumbar spine diseases due to overload are accepted as an occupational disease, with the processes of assessing and recognizing occupational diseases being specific to each country (6-10).
The possibility to recognize lumbar spine diseases from overload as an occupational disease has also been considered in the Czech Republic, where the law says that two sets of interrelated criteria, both clinical and hygienic, need to be met (11). The clinical criteria comprise pre-defined diagnostic parameters including the severity of the condition. To meet the occupational hygiene criteria, it is necessary to confirm that the person has worked under conditions known to contribute to occupational disease, according to the state of the art. Thus, to add a new item to the list of occupational diseases, these two sets of criteria must be defined at first.

The method proposed for evaluating the lumbar spine load at an individual level has already been described in detail $(12,13)$. Briefly, it uses the 3D Tecnomatix Classic JACK software to calculate the estimated compressive force on the L4/L5 intervertebral disc during work tasks. This article reports on the verification of the method and the first experiences with its application in practice. 


\section{MATERIALS AND METHODS}

To validate the method for evaluating lumbar spine load at an individual level, a sample of 55 individuals with chronic (i.e. lasting for at least six months) low back pain, with or without nerve root syndrome, working for at least three years under conditions that occupational medicine generally assumes to lead to lumbar spine overload was collected. The sample was selected by occupational practitioners. Work potentially leading to spine overload meant that the patients' occupational history mentioned tasks related to manipulating heavy loads, abnormal working postures, frequent bending and twisting of the trunk or extreme muscle strain. Individual evaluation at the site of work of the patients was carried out following an agreement between the patient/employee, employer and researcher. In individual subjects, the fulfilment of the proposed clinical and hygienic criteria was assessed separately. Here we report the assessment of the hygienic criteria.

\section{Process of Evaluating Lumbar Spine Load at Work- place}

Evaluating lumbar spine load is a multi-step process based on an objective assessment of particular working conditions focused on the presence of potentially high-risk work tasks.

Based on results of epidemiological studies with respect to potential lumbar spine overload, the potentially high-risk work tasks included in the study were manual handling of objects weighing $5 \mathrm{~kg}$ or more; abnormal working postures affecting the lumbar region with a rotation of $60^{\circ}$ or more; exerting vertical push and pull forces with the lumbar spine rotated at $40^{\circ}$ or more; and exerting horizontal push forces with the lumbar spine rotated at $40^{\circ}$ or more; as well as combinations of the above tasks with respect to their duration and frequency (14). The above potentially high-risk work tasks were described in detail and entered into four types of checklists. For each potentially high-risk work task, parameters concerning the working plan were determined, namely the distance of the object's centre of gravity, distance of hands from body and distance of hands from the object's centre of gravity, as these influence the estimated compressive force on the L4/L5 intervertebral disc (Fig. 1).

The first step in the evaluation process was filling in the identification sheet with basic anthropometric parameters of the individuals, their laterality (left-/right-handedness), length of the work shift, specificity of the work process and work tasks, etc.

Then, all tasks of a worker were monitored throughout his/ her work shift, with a special focus on potentially high-risk work tasks. At the same time, a time log of the work shift was kept and selected work tasks were video-recorded. The recordings were used for entering detailed information into the checklists (Fig. 2). For each task, duration, number and total time per shift were recorded.

Checklist 1 was used to record tasks associated with abnormal working postures:

- trunk rotation $\geq 60^{\circ}$ and bending $10^{\circ}$ or more, with forces of up to $10 \mathrm{~N}$ and distance of hands (Parameter A).

Checklist 2 was used to record tasks associated with manual handling of objects:

- trunk rotation $<40^{\circ}$, object weight $5 \mathrm{~kg}$ or more;

- trunk rotation $\geq 40^{\circ}$ and $<60^{\circ}$, object weight $3 \mathrm{~kg}$ or more; and

- trunk rotation $\geq 60^{\circ}$, object weight $1 \mathrm{~kg}$ or more, distance of hands from body (Parameter A), distance of the object's centre of gravity (Parameter B), and distance of hands from the object's centre of gravity (Parameter C).

Checklist 3 was used to record tasks associated with vertical push and pull forces:

- trunk rotation $<40^{\circ}$, force $50 \mathrm{~N}$ or more;

- trunk rotation $\geq 40^{\circ}$ and $<60^{\circ}$, force $30 \mathrm{~N}$ or more; and

- trunk rotation $\geq 60^{\circ}$, force $10 \mathrm{~N}$ or more, distance of hands from body (Parameter A), distance of the object's centre of gravity (Parameter B).

Checklist 4 was used to assess tasks associated with horizontal push and pull forces:

- trunk rotation $<40^{\circ}$, force $50 \mathrm{~N}$ or more;

- trunk rotation $\geq 40^{\circ}$ and $<60^{\circ}$, force $30 \mathrm{~N}$ or more; and

- trunk rotation $\geq 60^{\circ}$, force $10 \mathrm{~N}$ or more, and position of the upper limbs (Parameter D).

Tasks not meeting the above criteria were not recorded.

\section{Data Processing}

Information in the checklists was summarized with regard to frequency and duration to provide key data for evaluating lumbar spine load. Obtained values were processed using a special calculation module produced by simulating hundreds of ergonomic and

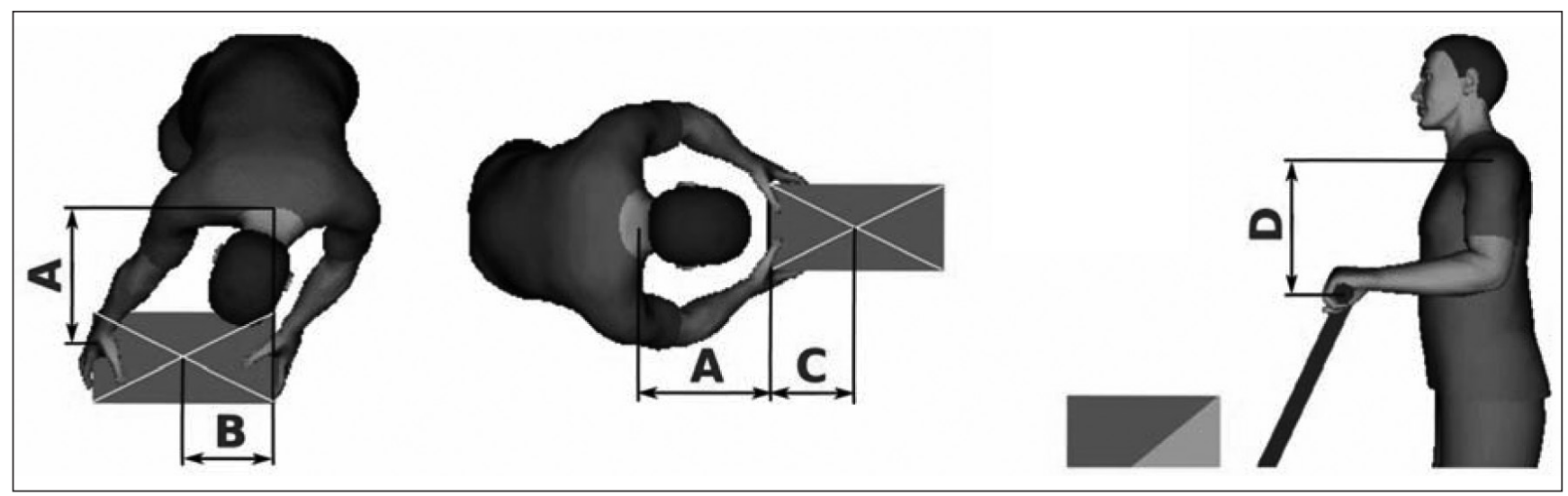

Fig. 1. Parameters of distances related to the working plane. 
biomechanical analyses with the 3D Tecnomatix Classic JACK software calculating the estimated compressive force on the L4/ L5 intervertebral disc during particular work tasks with respect to the worker's anthropometric parameters $(12,13)$ and comparing them with the US National Institute for Occupational Safety and Health (NIOSH) Work Practices Guide for Manual Lifting Limits for L4/L5 intervertebral disc compression, which is considered the main marker of lumbar spine load (15).

The guide states an action limit of 3,400 N for L4/L5 intervertebral disc compression during repetitive and long-term load and a maximum permissible limit of $6,400 \mathrm{~N}$ for single exertions (7, $15,16)$. Our reasons were similar to those described by Jäger et al. (17). The value of intervertebral disc compression is normally used in the process of evaluating lumbar spine overload when recognizing an occupational disease. Although it is only one part of the overall load on the lumbar spine. Sagittal and lateral shear forces occur in parallel with compression of the intervertebral disc and their values are often influenced by the value of compression. In the present literature, limits for shear forces regarding overloading of the lumbar spine have not been defined yet. Therefore, we did not take into consideration factors such as the sagittal and lateral shear forces.

For repetitive tasks, the limit value was set at 250 as stated in the EN 1005 standard (18). A maximum cumulative duration of high-risk tasks of 30 minutes was set in accordance with the Czech Government Regulation No. 361/2007 Coll., determining conditions for occupational health protection, as amended (19).

In the evaluation, the anthropometric parameters of the individuals and their laterality were taken into consideration and the results of each subject were compared with the limits.

\section{RESULTS}

To verify our previously proposed criteria for working conditions (12), work tasks were evaluated in the sample of 55 persons with various occupations. The largest subgroup (15 persons) were healthcare workers (Tables 1 and 2).

After considering all aspects of work, the criteria proposed for recognition of occupational disease were met in 24 patients ( 9 females, 15 males). The reasons were trunk bending and rotation combined with simultaneous handling of objects in 12 subjects, combination of trunk bending and simultaneous handling of objects in 9 subjects, and handling of objects in 3 subjects (Fig. 3).

A maximum intervertebral disc compression of $8,336 \mathrm{~N}$ was found in a male physiotherapist working in a long-term care fa-
Table 2. Subject's occupations and results of occupational hygiene assessment $(N=55)$

\begin{tabular}{|l|c|c|c|}
\hline \multirow{2}{*}{ Occupation } & \multirow{2}{*}{$\begin{array}{c}\text { Total } \\
\mathbf{n}\end{array}$} & $\mathbf{2}$ & $\%$ \\
\cline { 3 - 4 } & 13 & 4 & 30.7 \\
\hline Nurse, porter & 6 & 5 & 83.3 \\
\hline Production operator & 4 & 4 & 100.0 \\
\hline Forest worker & 4 & 2 & 50.0 \\
\hline Foundry worker & 3 & 3 & 100.0 \\
\hline Cabinetmaker, carpenter & 3 & 0 & 0 \\
\hline Cook, waiter & 2 & 2 & 100.0 \\
\hline Physiotherapist & 2 & 1 & 50.0 \\
\hline Locksmith & 1 & 0 & 0 \\
\hline Car mechanic & 1 & 0 & 0 \\
\hline Electrician & 1 & 0 & 0 \\
\hline Industrial painter & 1 & 0 & 0 \\
\hline Postman & 1 & 0 & 0 \\
\hline Shop assistant & 1 & 0 & 0 \\
\hline Window dresser & 1 & 0 & 0 \\
\hline Gardener & 1 & 1 & 100.0 \\
\hline Bricklayer & 10 & 2 & 20.0 \\
\hline Other workers & 55 & 24 & 43.6 \\
\hline Total & & & \\
\hline
\end{tabular}

cility manipulating patients with limited mobility, namely when lifting patients from beds and wheelchairs. These tasks were performed with his trunk bent at $60^{\circ}$ and rotated at $30^{\circ}$ while carrying objects weighing $20 \mathrm{~kg}$ or more. Such activities are considered to be the most high-risk tasks, with the action limit of 3,400 $\mathrm{N}$ for intervertebral disc compression being exceeded in $71 \%$ of cases, mostly workers in light and heavy industry (in some tasks), and the maximum permissible limit of $6,400 \mathrm{~N}$ being exceeded in some cases (7\%), especially healthcare workers moving and lifting patients, forest workers and production operators handling objects.

\section{DISCUSSION}

There are different ways to evaluate working conditions for the development of lumbar spine problems and their subsequent recognition as occupational disease in European countries. In most countries recognizing these diseases as occupational, the associa-

Table 1. Characteristics of subjects, length of their employment and duration of their spine problems

\begin{tabular}{|l|c|c|c|}
\hline Sample characteristics & $\begin{array}{c}\text { Males } \\
\mathrm{n=25}\end{array}$ & $\begin{array}{c}\text { Females } \\
\mathrm{n=30}\end{array}$ & $\begin{array}{c}\text { Total } \\
\mathrm{n=55}\end{array}$ \\
\hline Age at enrollment (years) & 45.4 & 45.8 & 45.6 \\
\hline Weight (kg) & 86.5 & 77.1 & 81.4 \\
\hline Height (cm) & 178.0 & 168.0 & 173.0 \\
\hline Length of employment (years) & 18.8 & 13.0 & 15.6 \\
\hline Duration of lumbar spine problems (years) & 8.2 & 7.5 & 7.9 \\
\hline Length of employment before the onset of lumbar spine problems (years) & 12.1 & 8.7 & 10.2 \\
\hline
\end{tabular}




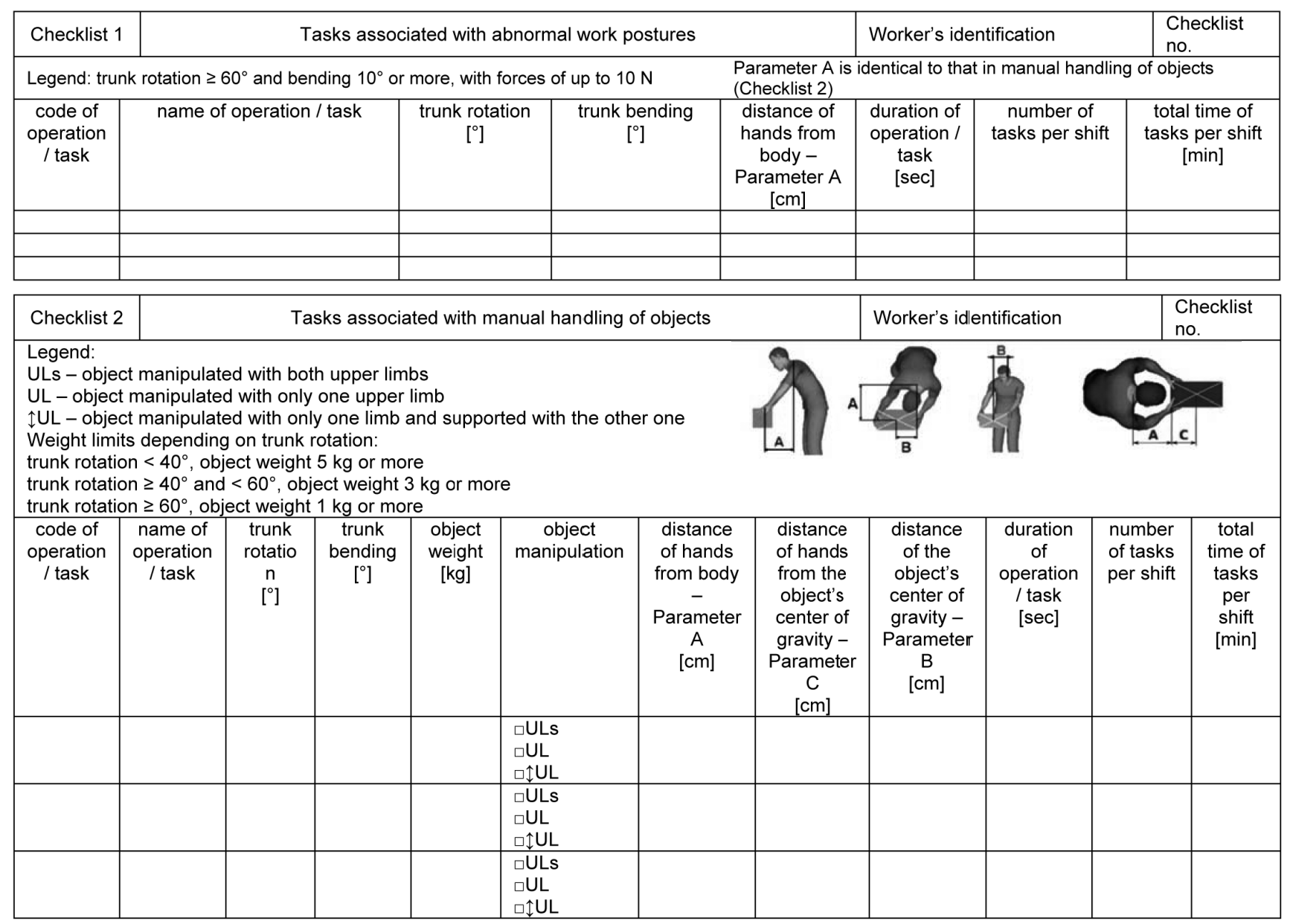

\begin{tabular}{|c|c|c|c|c|c|c|c|c|c|c|c|}
\hline Checklist 3 & & asks asso & ted & & ical force & (upwards / do & nnwards) & \begin{tabular}{|l} 
Worker \\
\end{tabular} & 's identification & & Checklist no. \\
\hline $\begin{array}{l}\text { Legend: } \\
\downarrow \text { ULs, UL }-c \\
\text { Force limits } \\
\text { trunk rotation } \\
\text { trunk rotation } \\
\text { trunk rotation }\end{array}$ & $\begin{array}{l}\text { ownward forc } \\
\text { epending on } \\
<40^{\circ} \text {, force } \\
\geq 40^{\circ} \text { and }< \\
\geq 60^{\circ} \text {, force } 1\end{array}$ & $\begin{array}{l}, \uparrow U L s, ~ \\
\text { runk rotat } \\
50 \mathrm{~N} \text { or } \mathrm{mc} \\
\mathrm{i} 0^{\circ}, \text { force } \\
0 \mathrm{~N} \text { or } \mathrm{mc}\end{array}$ & No & & ce, $\uparrow U L$ & $\begin{array}{r}\text { object manipul } \\
\mathrm{Pa} \\
\mathrm{Ch}\end{array}$ & $\begin{array}{l}\text { ted with only o } \\
\text { ameters } A \text { and } \\
\text { ecklist 2) }\end{array}$ & ore limb and su & $\begin{array}{l}\text { Ipported with } t \\
\text { I to those in } \mathrm{m}\end{array}$ & $\begin{array}{l}\text { e other one } \\
\text { anual handling }\end{array}$ & of objects (see \\
\hline $\begin{array}{c}\text { code of } \\
\text { operation } \\
\text { / task }\end{array}$ & $\begin{array}{c}\text { name of } \\
\text { operation } \\
/ \text { task }\end{array}$ & $\begin{array}{c}\text { trunk } \\
\text { rotation } \\
{\left[{ }^{\circ}\right]}\end{array}$ & & & $\begin{array}{c}\text { force } \\
\text { applied } \\
{[\mathrm{N}]}\end{array}$ & $\begin{array}{c}\text { object } \\
\text { manipulation }\end{array}$ & $\begin{array}{c}\text { distance - } \\
\text { Parameter } \\
\text { A } \\
{[\mathrm{cm}]}\end{array}$ & $\begin{array}{c}\text { distance - } \\
\text { Parameter } \\
\text { B } \\
{[\mathrm{cm}]}\end{array}$ & 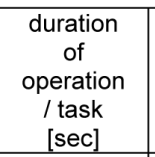 & $\begin{array}{l}\text { number of } \\
\text { tasks per } \\
\text { shift }\end{array}$ & $\begin{array}{l}\text { total time of } \\
\text { tasks per shift } \\
\text { [min] }\end{array}$ \\
\hline & & & & & & $\begin{array}{l}\text { aUULs,UL } \\
\text { व†ULs,UL } \\
\text { aUUL }\end{array}$ & & & & & \\
\hline & & & & & & $\begin{array}{l}\text { aULs,UL } \\
\text { âLs,UL } \\
\text { âUL }\end{array}$ & & & & & \\
\hline & & & & & & 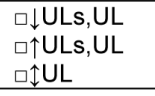 & & & & & \\
\hline Checklist 4 & & & asks & soc & ted with $\mathrm{H}$ & rizontal forces & & Worl & ker's idlentifica & & Checklist no. \\
\hline $\begin{array}{l}\text { Legend: } \\
\text { Force limits } \\
\text { trunk rotatior } \\
\text { trunk rotatior } \\
\text { trunk rotatior } \\
\text { Upper limb p } \\
0 \% \text { - upper } \\
50 \% \text { - upper } \\
100 \% \text { - upp }\end{array}$ & $\begin{array}{l}\text { epending on } \\
<40^{\circ} \text {, force } \\
\geq 40^{\circ} \text { and }< \\
\geq 60^{\circ} \text {, force } \\
\text { sition - para } \\
\text { mbs stretche } \\
\text { limbs flexed } \\
\text { r limbs stretcl }\end{array}$ & $\begin{array}{l}\text { trunk rota } \\
50 \mathrm{~N} \text { or } \mathrm{m} \\
60^{\circ}, \text { force } \\
10 \mathrm{~N} \text { or } \mathrm{m} \\
\text { meter } \mathrm{D}: \\
\text { d along th } \\
\text { at elbows } \\
\text { hed forwa }\end{array}$ & & & & & Paran & neter D & $\begin{array}{l}\text { ameter } B \text { is id } \\
\text { Idling of objec }\end{array}$ & $\begin{array}{l}\text { ntical to that } \\
\text { s (see Check }\end{array}$ & $\begin{array}{l}\text { manual } \\
\text { st 2) }\end{array}$ \\
\hline $\begin{array}{l}\text { code of } \\
\text { operation / } \\
\text { task }\end{array}$ & $\begin{array}{c}\text { name of } \\
\text { operation / } \\
\text { task }\end{array}$ & $\begin{array}{r}\text { tru } \\
\text { rota } \\
{\left[{ }^{\circ}\right.}\end{array}$ & & & $\begin{array}{l}\text { unk } \\
\text { ding } \\
\text { ding }\end{array}$ & $\begin{array}{c}\text { force } \\
\text { applied } \\
{[\mathrm{N}]}\end{array}$ & $\begin{array}{c}\text { upper limb } \\
\text { position - } \\
\text { Parameter } \\
D \\
{[\%]}\end{array}$ & $\begin{array}{c}\text { distance - } \\
\text { Parameter } \\
\text { B } \\
{[\mathrm{cm}]}\end{array}$ & $\begin{array}{c}\text { duration of } \\
\text { operation / } \\
\text { task } \\
\text { [sec] }\end{array}$ & $\begin{array}{l}\text { number of } \\
\text { tasks per } \\
\text { shift }\end{array}$ & $\begin{array}{l}\text { total time of } \\
\text { tasks per } \\
\text { shift } \\
\text { [min] }\end{array}$ \\
\hline & & & & & & & & & & & \\
\hline & & & & & & & & & & & \\
\hline
\end{tabular}

Fig. 2. Checklists 1-4. 


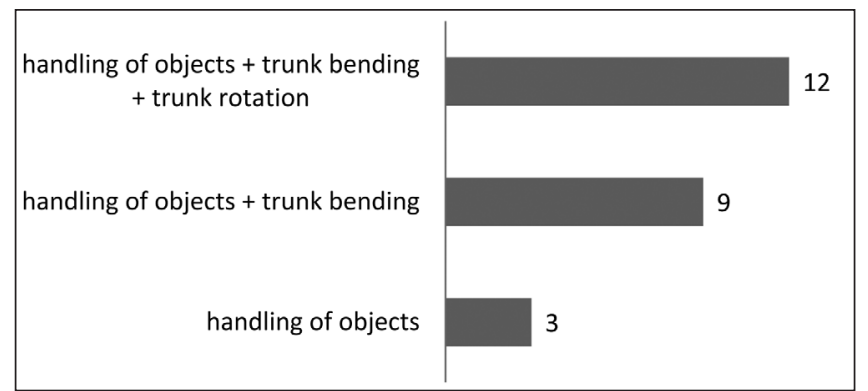

Fig. 3. Detected causes of lumbar spine overload in patients meeting the criteria.

tion between lumbar spine disease and patients' work is individually assessed by various experts such as physicians of various specialties as well as ergonomists or occupational hygienists (6, 10). In some countries, the causal relationship between lumbar spine overload and disease in particular workers is evaluated using computer (Germany) or mathematical (Slovakia) models (6-8).

In Slovakia, for example, lumbar spine diseases have been recognized as occupational since 2007 (7). An essential prerequisite for the recognition is that the occupational risk is verified by occupational hygiene specialists (6). At first, a preliminary assessment is conducted, with points being assigned to tasks related to lifting or carrying objects, trunk rotating and bending and whole-body vibration as well as to job satisfaction. The preliminary assessment is based on a model developed by Lötters et al. (3). If the achieved score suggests occupational damage to the lumbar spine, a detailed assessment of occupational factors follows, which is based on work task description, a time log, physical activity assessment using energy expenditure, analysis of working postures during individual tasks including unacceptable postures with regard to their duration, ways of handling objects, their lifting and carrying. Additionally, analyses of the work-rest cycle and workplace ergonomics are performed, including the so-called contributing factors such as lighting or microenvironmental conditions. Moreover, the use of personal protective equipment or employees' awareness of occupational hazards are also investigated $(6,7)$. The numbers of registered lumbar spine diseases in Slovakia from 2007 to 2015 did not exceed 2 cases per year on average.

In Germany, the main guidance for recognizing lumbar spine diseases as occupational requires the assessment of working conditions including handling of heavy objects and working with the trunk extremely bent or the upper body bent at $90^{\circ}$ or more, with the load occurring during at least 60 shifts per year over a period of at least 10 years (8).

The Belgian criteria for occupational exposure are based on meeting conditions defined for risks caused by carrying heavy objects, mechanical vibration in a sitting position or combination of the two risks. The risk caused by carrying heavy objects is assessed by calculating the total compressive force on the L5/ S1 intervertebral disc after correction for movement with lifting of objects and associated with trunk rotation. Manifested disease must be preceded by the high-risk occupational activities lasting for at least 7 years, with the load being present on at least 60 work days of each year included (9).

In the above countries, the key tasks considered when assessing occupational exposure are those requiring handling of objects in combination with bending of the trunk in the lumbar region. These causes of overload were found in all patients included in our study. Until recently, however, no method was available to objectively quantify the outcome of multiple work factors simultaneously affecting the lumbar spine during a work shift for common occupational hygiene practice. It has been verified that the presented approach is suitable for such assessments.

Our proposed method for evaluating lumbar spine load under particular working conditions with a developed calculation module uses the L4/L5 intervertebral disc compression limits recommended by the NIOSH (15). Work tasks exerting a force of less than 3,400 $\mathrm{N}$ may be considered as activities with acceptable risk for the development of lumbar spine damage even in case of repetitive and long-term load. By contrast, tasks producing a force of more than $6,400 \mathrm{~N}$ even on single occasions may represent a high risk of damage to the lumbar spine. The same approach to the risk of lumbar spine load with regard to limits recommended by the NIOSH was used in a study by Ferguson et al. (16).

In France, on the other hand, a restrictive list of occupations is given and a minimum 5 years of exposure must be fulfilled (20). The situation is similar in Lithuania. In several countries, the hygienic criteria are not explicitly given and the evaluation of the working condition is done on an individual basis, however, the measurement of motions and forces is not used (6).

The mean length of employment in our study was 15.6 years (15.8 years in the group of individuals meeting the proposed criteria and 15.4 years in those who did not meet the criteria). Individuals who exceeded the maximum permissible limit of $6,400 \mathrm{~N}$ worked for 16 years on average.

Most employers involved in the pilot study showed a very positive and responsible attitude. None of the employers and employees refused to participate. Some of the employers were interested in the outcomes and, when the proposed limits were exceeded, also in analyzing the causes and even helping to solve the situation. The proposed method also seems to be suitable for preventing health risks in work tasks related to lumbar spine overload.

The practical evaluation of lumbar spine load using the proposed method requires collection of detailed data needed, as well as descriptions of individual work tasks and their combinations throughout a work shift (or even several shifts if the work tasks vary), analysis of videos recorded, time-stamping, expertise and experiences. Moreover, the assessment is relatively timeconsuming. Therefore, clinical occupational practitioners should ask for such evaluation only after all clinical and other conditions are met and the association between the person's occupation and lumbar spine disease is reasonably suspected.

Some of the common work tasks with recorded exceeding of the proposed criteria were identical to those in Table 98 of the French list (20). Those are connected to the work of healthcare workers removing and lifting patients, work in the food industry, distribution and storage of products, and work in forest services.

If the set of clinical criteria was applied to the participants in the present study, they would be met by only 11 individuals, meaning that only in these cases evaluation of working conditions would be required. It must be borne in mind that even in cases when the clinical criteria are clearly met, the objective assessment of working conditions may demonstrate that the occupational hygiene criteria for recognition of an occupational disease are not fulfilled. 
In the Czech Republic, the occupational hygiene criteria play one of the key roles in recognizing lumbar spine diseases as occupational. Therefore, it was necessary to perform a pilot study verifying the proposed method, both to confirm that the suggested limits are correct and to see whether it may be practically used in patients' actual working conditions. As seen from the results, the answer to both questions was positive.

\section{CONCLUSION}

The proposed method for evaluating lumbar spine load not only aids in determining whether working conditions are met or not when assessing occupational diseases but it may also be used in prevention such as in ergonomic workplace assessment, identifying high-risk work tasks and operations that, when regularly repeated, may give rise to lumbar spine diseases. However, if effective preventive measures are introduced, occupational lumbar spine overload may be eliminated in many cases.

\section{Acknowledgements}

The study was supported by the Ministry of Health of the Czech Republic (MH CZ) project no. IGA MZ ČR NT/14471 - 3 and by MH CZ - DRO (National Institute of Public Health - NIPH, IN 75010330).

\section{REFERENCES}

1. Institute of Health Information and Statistics of the Czech Republic Terminated cases of incapacity for work for disease or injury 2012 [Internet]. Prague: Institute of Health Information and Statistics of the Czech Republic; 2013 [cited 2016 Sep 16]. Available from: http://www. uzis.cz/en/publications/terminated-cases-incapacity-work-disease-orinjury-2012.

2. Peng B, Fu X, Pang X, Li D, Liu W, Gao C, et al. Prospective clinical study on natural history of discogenic low back pain at 4 years of followup. Pain Physician. 2012;15(6):525-32.

3. Lötters F, Burdorf A, Kuiper J, Miedema H. Model for the work-relatedness of low back pain. Scand J Work Environ Health. 2003;29(6):431-40.

4. Junghanns H. The Spine in occupational medicine. Stuttgart: HippokratesVerlag; 1979. (In German.)

5. Hart R, et al. Degenerative diseases of the spine. Prague: Galén; 2014 (In Czech.)

6. Laštovková A, Nakládalová M, Fenclová Z, Urban P, Gad’ourek P, Lebeda $\mathrm{T}$, et al. Low-back pain disorders as occupational diseases in the Czech Republic and 22 European countries: comparison of national systems, related diagnoses and evaluation criteria. Cent Eur J Public Health. 2015; 23(3):244-51
7. Čierna J, Bátora I. Injury of vertebral column as an occupational disease. Ces Prac Lek. 2006;7(3):162-4. (In Slovak.)

8. Decree No. 2108 of the Ministry of Labor and Welfare of September 1, 2006, occupational diseases ruling - occupational diseases leaflets. Bundesarbeitsblatt. 2006;(10):30. (In German.)

9. Occupational disease 1.605.03 - Mono or polyradicular syndrome - exposure to occupational hazards and compensation [Internet]. Brussels: Occupational Diseases Fund; 2005 [cited 2016 Sep 16]. Available from: https://fedris.be/sites/default/files/assets/FR/Documentation_medicale/ Publications scientifiques/Criteres/syndrome mono ou polyradiculaire. pdf. (In French.)

10. Pelclova D, Lastovkova A, Fenclova Z, Ridzon P, Urban P, Hlavkova J, et al. Occupational risk factors in the chronic lumbar vertebral column diseases in European countries. In: 31st International Congress on Occupational Health; 2015 May 31 - June 5; Seoul, Korea.

11. Nakládalová M, Urban P, Hlávková J, Ehler E, Ridzoň P, Boriková A, et al. Low back pain as an occupational disease. Prac Lek. 2014;66(23):94-7. (In Czech.)

12. Hlávková J, Lebeda T, Tichý T, Gad’ourek P, Urban P, Nakládalová M, et al. Evaluation of lumbar spine load by computational method in order to acknowledge low-back disorders as occupational diseases. Cent Eur J Public Health. 2016;24(1):58-67.

13. Gad'ourek P, Lebeda T, Hlávková J, Urban P, Ehler E, Ridzoň P, et al. Using ergonomic software TECNOMATIX JACK when assessing workload for lumbar spine disease. In: Osina O, Mušák L, editors. Occupational medicine and toxicology: new pieces of knowledge and experience 2. Martin: Comenius University, Jessenius Faculty of Medicine; 2014. p. 65-9. (In Czech.)

14. Kuiper JI, Burdorf A, Frings-Dresen MH, Kuijer PP, Spreeuwers D, Lötters FJ, et al. Assessing the work-relatedness of nonspecific low-back pain. Scand J Work Environ Health. 2005 Jun;31(3):237-43.

15. Waters TR, Putz-Anderson V, Garg A, Fine LJ. Revised NIOSH equation for the design and evaluation of manual lifting tasks. Ergonomics. 1993 Jul;36(7):749-76.

16. Ferguson SA, Marras WS, Burr D. Workplace design guidelines for asymptomatic vs. low-back-injured workers. Appl Ergon. 2005 Jan; 36(1):85-95

17. Jäger M, Geiß O, Bergmann A, Bolm-Audorff U, Ditchen D, Ellegast $\mathrm{R}$, et al. Biomechanical analyses on lumbar load within the German Spine Study. Zentralbl Arbeitsmed Arbeitschutz Ergonomie. 2007 Sep;57(9):264-276. (In German.)

18. CSN EN 1005-4+A1. Safety of machinery - Human physical performance - Part 4: Evaluation of working postures and movements in relation to machinery. Prague: Czech Office for Standards, Metrology and Testing; 2009. (In Czech.)

19. Decree No. 361 of the Government of the Czech Republic of December 12 , 2007, determining conditions for occupational health protection. Sbírka zákonů ČR. 2007 Dec 28;Pt 111:5086-236. (In Czech.)

20. Virtual School of Occupational Medicine. Table 98 of the General Regime: Lumbar spine chronic affections caused by carrying heavy loads [Internet]. [cited 2016 Sep 19]. Available from: http://www.uvmt.org/ sections.php?op=viewarticle\&artid=213. (In French.) 